
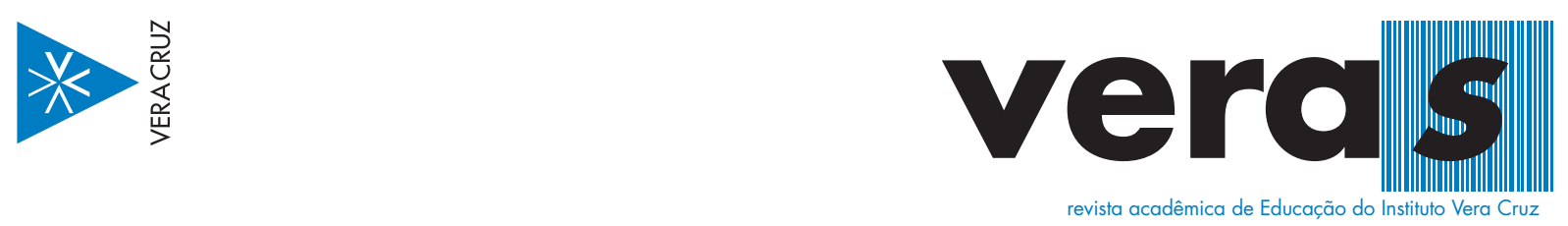

ISSN 2236-5729

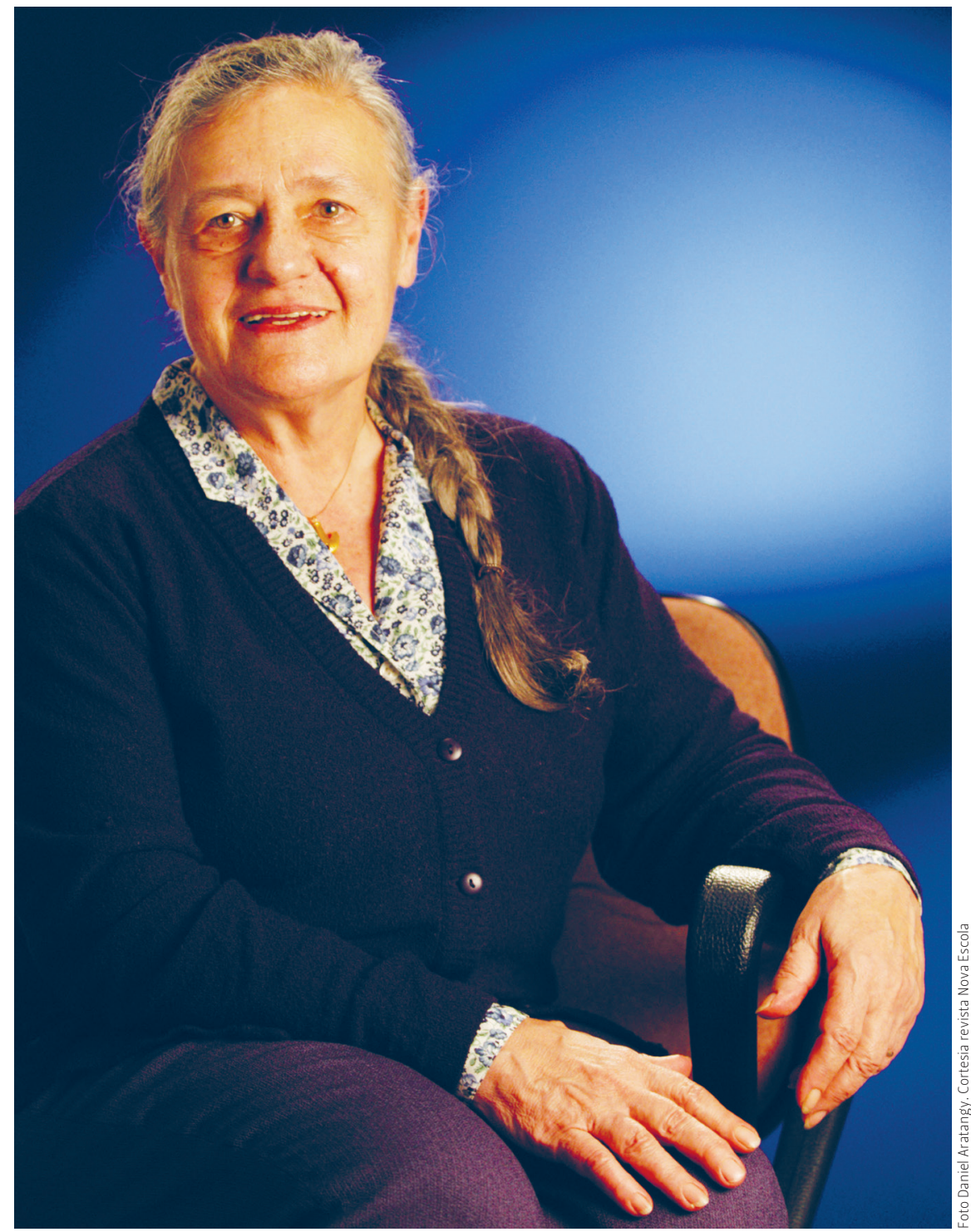

\title{
Entrevista: Emilia Ferreiro
}

"A informação pode estar a um clique na tela, mas não o conhecimento"

Por Ricardo Prado, editor da Revista Veras, e Renata Lopes Costa Prado, professora adjunta do Instituto de Educação de Angra dos Reis da Universidade Federal Fluminense (IEAR/UFF) 
Emilia Ferreiro é uma das mais influentes pesquisadoras de psicologia e educação de nosso tempo. Suas contribuições para a compreensão da psicogênese da língua escrita revolucionaram conceitos e modos de abordar os processos de alfabetização. A partir delas, a ênfase de estudos na área deixa de ser o ensino do sistema de escrita alfabética e passa a focar os modos pelos quais as crianças aprendem a ler e a escrever, de forma ativa e contextualizada, em seus entornos socioculturais.

Nascida na Argentina, Emilia formou-se em psicologia e fez seu doutorado na área de Psicologia Genética na Universidade de Genebra, sob a orientação de Jean Piaget. Atualmente é pesquisadora do Departamento de Investigações Educativas do Instituto Politécnico Nacional, no México. Foi professora da Universidade de Buenos Aires e professora convidada da Universidade de Roma, da Universidade Autónoma de Madrid, da Escola Prática de Altos Estudos da Sorbonne, da Universidade Federal de Pernambuco e da Universidad Nacional Autónoma de México.

Nesta entrevista sobre as relações entre alfabetização e novas tecnologias da informação e comunicação, concedida à distância em junho de 2016, a pesquisadora alerta para a pouca atenção dada ao tema pelos professores. Para ela, poucos docentes parecem se dar conta das transformações, tanto em termos de didática quanto de pesquisa, que uma revolução tecnológica da dimensão da que estamos vivendo traz à prática em sala de aula. Ressaltando o movimento contrário em relação ao suporte escrito das gerações que hoje se encontram nas salas de alfabetização (as crianças saíram "da tela ao papel", enquanto suas professoras fizeram o caminho inverso, ou seja, foram "do papel para a tela"), Emilia Ferreiro analisa que os desafios para o docente que promove a introdução da criança ao sistema de escrita aumentaram: "Estar alfabetizado para a sociedade do início do século XXI requer muito mais do que se pretendia da alfabetização do início do século XX. Isto é grave, porque os atrasos que arrastamos não se resolvem tratando de fazer mais do mesmo". Tamanha mudança traz o risco da incerteza, ela reconhece, mas admite também que se sente privilegiada por participar dessa revolução tecnológica. Dentre as incertezas apontadas nesta entrevista, destacam-se a instabilidade do suporte dos textos e o papel dúbio da escola em relação ao uso da tecnologia por parte dos alunos. 
A mais reconhecida voz da teoria piagetiana aplicada aos estudos sobre língua escrita também traz uma boa notícia para educadores, estudiosos e pesquisadores interessados nos processos de alfabetização de crianças, jovens e adultos e, mais especificamente, em sua obra: a Universidade Nacional de Rosário e o seu Instituto de Cooperação LatinoAmericana acabam de lançar o site da Cátedra Estudios Interdisciplinarios en Alfabetización Dr ${ }^{\mathrm{a}}$. Emilia Ferreiro (http:// catedraemiliaferreiro.unr.edu.ar), com acesso livre e gratuito a vídeos, entrevistas, bibliografia e material multimídia com informações (em espanhol) a respeito de como as crianças pequenas raciocinam sobre a escrita e orientações para ler os textos escritos por elas com base nas pesquisas desenvolvidas pela educadora desde o seminal Psicogênese da Língua Escrita, escrito em parceria com Ana Teberosky e publicado em 1979 (no Brasil, em 1984).

Revista Veras: Como os significados de leitura e de escrita vêm se transformando na era da internet?

Emilia Ferreiro: Sem dúvida, fazemos parte de uma revolução global nos meios de acesso, produção e disseminação de textos e imagens. Essa revolução afeta todas as profissões, das mais braçais e menos qualificadas às mais conceituais e com mais créditos acadêmicos de pós-graduação. Portanto, a profissão docente está incluída. Me preocupa, ao extremo, que os docentes de nossos países não priorizem uma discussão sobre a questão.

Participar de uma revolução tecnológica tão importante é um privilégio, mas inclui, ao mesmo tempo, o risco da incerteza. De que forma o meu modo particular de exercer a docência ou a pesquisa será afetado? Seguramente será afetado, mas de que maneira? Veja um exemplo prático: o mecânico que dava suporte técnico ao meu automóvel agora usa um sofisticado sistema informatizado porque já não consegue detectar falhas no motor sem utilizar esse sistema.

Revista Veras: Que novos desafios as tecnologias da informação e a internet trazem para o educador alfabetizador?

Emilia Ferreiro: Primeiramente precisamos entender que a alfabetização não é um estado, mas um processo. Ao mesmo tempo, devemos entender que os requisitos para dizer que alguém 
está "devidamente alfabetizado" não são fixados pela escola, mas pela sociedade. Estritamente, a alfabetização é uma construção histórica que vem mudando com o tempo e com as demandas sociais. E que continuará mudando. Há 50 anos, ninguém podia supor que os telefones móveis praticamente substituiriam os telefones fixos, com uma rápida penetração massiva, atingindo todos os países, todas as idades e grupos sociais. Apenas 50 anos atrás ninguém poderia supor que pesquisar na internet, preencher formulários na tela e, inclusive, efetuar pagamentos ou compras na tela seriam comportamentos essenciais de uma pessoa alfabetizada. Os dispositivos digitais mudaram as condições de trabalho e mudaram o cotidiano das pessoas.

Estar alfabetizado para a sociedade do início do século XXI requer muito mais do que se pretendia da alfabetização do início do século XX. Isto é grave, porque os atrasos que arrastamos não se resolvem tratando de fazer mais do mesmo. A informação pode estar à distância de um clique na tela, mas o conhecimento não se produz automaticamente com nenhum clique.

0 conhecimento exige uma atividade discriminadora e integradora do sujeito psicológico, do sujeito cognoscente, para transformar a informação em conhecimento. A informação é um dado externo ao sujeito. 0 conhecimento é um resultado da atividade do sujeito cognoscente. Para reconhecer a informação relevante e confiável não basta um clique. Construir critérios para distinguir os sites confiáveis dos "outros" não se resolve com um clique. Também o sujeito psicológico cognoscente deve intervir para encontrar a informação que procura, agregando "informação confiável" a seus critérios de busca.

Revista Veras: Que temas relativos à alfabetização e à introdução nas culturas do escrito a senhora considera como importantes linhas de investigação a serem aprofundadas?

Emilia Ferreiro: Gostaria de ressaltar um aspecto dos novos dispositivos digitais que cria uma franca oposição ao "suporte do impresso". A tecnologia do livro é uma tecnologia estável. A tecnologia dos jornais em papel também. A tecnologia dos outros formatos em papel (volantes, folhetos) também é estável. A sua estabilidade é uma construção histórica, mas, para os usuários, essa história é irrelevante. 0 que importa é a estabilidade dos formatos. 
Opostamente, as telas nos colocam diante de dispositivos altamente instáveis. A instabilidade pode ser fruto da novidade, mas, desde o surgimento dos primeiros PCs, em agosto 1981, até os dias de hoje, a concorrência voraz entre as empresas tem privilegiado as mudanças promovidas como tais em detrimento da estabilidade das funções. Somos obrigados a trocar o PC a cada quatro ou cinco anos porque não conseguimos atualizar os programas. De repente, descobrimos que não podemos mais ler os DVDs, muito menos os CDs. Perdemos informação devido a uma atualização que apenas prometia maior eficiência.

Outro exemplo: os telefones móveis não param de acumular funções. Aceitam mensagens de texto bem como mensagens de voz, são calculadoras, máquinas fotográficas, relógios com funções de despertador, têm conexão com a internet e quem sabe o que mais no futuro imediato. Vínhamos de um mundo onde, a cada uma dessas funções, correspondiam objetos diferentes e, de repente, a forma do suporte não tem nada a ver com a sua função. Também são instáveis os sites ou "páginas" da internet em que obtivemos determinada informação. Nos trabalhos acadêmicos precisamos mencionar a data da consulta porque nada garante que, dias depois, o site e a informação continuem existindo no ciberespaço.

A instabilidade é a regra: instabilidade dos sites, das informações, dos dispositivos de busca, dos programas e de suas funções, dos ícones, de tudo, enfim. Isso se contrapõe fortemente com a estabilidade da informação impressa no formato "livro".

Revista Veras: Como pensar um currículo considerando-se esse aluno nativo digital?

Emilia Ferreiro: É preciso notar que as crianças que estão na escola primária não passaram do papel às telas, mas, ao contrário, das telas ao papel; telas da TV, dos celulares ou de outros dispositivos. Sei muito bem que a tela da TV não é comparável às outras, mas, na dicotomia dos tempos atuais, o acesso às telas (de diversos tipos, interativas ou não) é muito precoce e, em muitos casos, antecede o acesso ao texto ou à imagem no papel. Cada vez mais crianças fazem suas primeiras incursões na escrita por meio de um teclado, principalmente para encontrar no Google a animação que querem ver.

Inversamente, as professoras dessas crianças foram alfabetizadas 
no papel e tiveram acesso às telas já jovens ou adultas. Isso provoca uma importante defasagem entre gerações. Elas viram a chegada das telas de computadores e celulares. Seus alunos nasceram com essas telas já instaladas na sociedade.

Revista Veras: E a relação da escola, enquanto instituição, com a tecnologia, como a senhora avalia o momento atual?

Emilia Ferreiro: A relação da instituição escolar com as tecnologias é um tema imenso que não pode ser desenvolvido em uma entrevista. É preciso uma olhada histórica para entender o lento processo de gestação de "instrumentos de ensino" que acompanhou o nascimento da escolaridade básica obrigatória e as reações de rápida aceitação ou franca rejeição que logo ocorreram. Por exemplo: a pena metálica foi rapidamente assimilada, ao passo que, décadas depois, a caneta foi objeto de franca rejeição porque, dizia-se, iria "arruinar a letra" dos alunos.

Atualmente, temos escolas onde é proibido a entrada de alunos com celulares, ao passo que, em outras, o professor se permite a liberdade de deixar o dele tocando no meio da aula. Há escolas onde se pesquisa mais pela internet do que nas bibliotecas. Ao passo que, em outras, o uso da internet para fins escolares está praticamente proibido porque os alunos se limitam a "cortar e colar" sem ler. Poderia seguir aqui com vários exemplos.

De qualquer modo, poderia assumir-se que o verbo "ler" designa a mesma atividade, independentemente do tipo de texto, do tipo de suporte e do propósito leitor. Mas não é assim. Para ficar em um único exemplo: a pesquisa de informação por meio do Google exige um modo de leitura diferente da consulta do índice em um livro ou enciclopédia. Primeiro, porque surgirá uma impressionante lista de lugares onde a informação pesquisada parece estar. Os buscadores respondem à pergunta escrita com uma lista de várias páginas. Essa lista põe todos os sites potencialmente úteis em pé de igualdade - os confiáveis e os demais. Como construir critérios de confiabilidade na internet para não perder o foco e encontrar a informação necessária? Como identificar em poucas linhas com muitas reticências o site onde convém entrar? Como fugir à tentação de utilizar apenas os dois primeiros sites da lista oferecida pelo buscador? E, uma vez escolhido o site, como pesquisar nele? Como saber se é confiável? Etc., etc., etc. 